\section{Ditadura militar: a memória jornalística como parte da revisão histórica}

Lívia Assad de MORAES ${ }^{1}$

Resumo: O trabalho pretende demonstrar a importância da memória jornalística nos estudos sobre a ditadura militar no Brasil (1964-1985). Defendemos a ideia de que lembranças, relatos e reavaliações de jornalistas, baseados em experiências nas redações, contribuem tanto para a construção histórica do passado recente da profissão quanto, de um modo mais amplo, para debates, análises e reflexões sobre a época. Destacamos o papel desses profissionais como atores sociais no processo de formação de uma memória coletiva sobre o contexto político e cultural durante o regime militar, no qual a prática do jornalismo se desenrolou sob coerção ideológica (censuras oficial e empresarial) e tentativas de resistência em favor da liberdade de expressão.

Palavras-chave: Memória; ditadura militar; jornalismo; mídia e processo político brasileiro.

\section{Dictadura militar: la memoria periodísti- ca como parte de la revisión histórica}

Resumen: El trabajo se propone a evidenciar la importancia de la memoria periodística en los estudios sobre la dictadura militar en Brasil (1964-1985). La idea clave es que los recuerdos, relatos y evaluaciones de periodistas, basados en experiencias en las redacciones contribuyen para la construcción histórica del passado reciente de la carrera y, de modo más amplio, para debates, análisis y reflexiones sobre la época. Se destaca el rol de estos profesionales como actores sociales en el proceso de formación de una memoria colectiva sobre el contexto político

1 Lívia Assad de Moraes é jornalista formada pela Pontifícia Universidade Católica do Rio de Janeiro (PUC-Rio) e mestranda no Programa de Pós-Graduação em Cultura e Territorialidades da Universidade Federal Fluminense (UFF), com bolsa da Fundação Carlos Chagas Filho de Amparo à Pesquisa do Estado do Rio de Janeiro (FAPERJ). Correio eletrônico: livia.assad@hotmail.com y cultural durante el regimen militar, en que la práctica del periodismo se desarrolló bajo la coerción ideológica (censuras oficial y empresarial) y tentativas de resistencia en favor de la libertad de expresión.

Palabras clave: Memoria, dictadura militar, periodismo, medios y proceso político brasileño.

\section{Introdução: o jornalismo brasileiro na ditadura militar}

A década de 1960 foi um momento de transformações na vida política, social e cultural do país. $\mathrm{O}$ advento do golpe militar de 1964 inaugurou um período de sérias restrições às liberdades de imprensa e de expressão, afetando sobremaneira as atividades jornalísticas e, consequentemente, o direito de a sociedade informar e ser informada com independência. Nos anos da ditadura (1964-1985), a censura imposta pelo regime impedia a publicação de reportagens, artigos, entrevistas, documentos e materiais artísticos que pudessem, no juízo das autoridades militares e policiais, afetar a "segurança nacional" e a "ordem pública". Além disso, portarias e decretos governamentais proibiam o funcionamento de determinadas publicações opositoras, com a mesma alegação. Nesse contexto, jornalistas foram cerceados e, não raro, impedidos de cumprir plenamente sua função principal: a de informar os leitores com liberdade. $\mathrm{Na}$ maioria das vezes não havia, portanto, espaço para abordagens mais críticas sobre os assuntos tratados ou para se explorar as questões e os fatos em suas diversas faces.

Com a interrupção do processo democrático, o governo militar criou órgãos destinados ao controle de dados e informações, aí incluídos dossiês sobre opositores da ditadura. Entre esses órgãos, se encontrava o Serviço Nacional de Informações (SNI), fundado em junho de 1964 com o objetivo de supervisionar e coordenar as atividades de informações e contrainformações no Brasil e no exterior. Além do SNI, entraram em funcionamento, nos anos posteriores, o Departamento de Operações de Informações - Centro de Operações de Defesa Interna (DOI-CODI), que se incumbia de prender, sequestrar e torturar pessoas que agissem contra o regime, o DOPS (Departamento de Ordem Política e Social), o Centro de Informações da Marinha (CENIMAR), o Centro de Informações do Exército (CIE), o Centro de Informações da Aeronáutica (CISA) e as Segundas Seções das Forças Armadas (FICO, 2004).

Maria Aparecida de Aquino afirma que "esse formidável instrumental repressivo objetivava o exer- 
cício de uma vigilância cerrada sobre todos os setores da sociedade, visando detectar e punir toda e qualquer tentativa explícita ou implícita de 'subversão' à ordem instaurada” (AQUINO, 1999, p. 15). Isso tem a ver com o fato de que os governos militares encaravam como necessário "o controle da informação a ser divulgada, para preservar a imagem do regime, num exercício de ocultação que passa, inclusive, pela negação de visibilidade, ao leitor, de suas próprias condições de vida". (AQUINO, 1999, p. 15).

Como justificativa à censura, os militares defendiam que "se a liberdade de imprensa era condição necessária para a democracia, para a democracia 'aperfeiçoada' seria fundamental uma imprensa 'aperfeiçoada', sob a tutela dos militares” (ARAÚJO, 2005)

$\mathrm{Na}$ análise de Marialva Barbosa, "O argumento usado pelo Governo para a instauração da censura coloca em evidência o papel que se atribui naquele momento aos meios de comunicação: além de informar, estes deveriam 'orientar' a população, tutelados pelo Executivo" (BARBOSA, 2007, p.189).

Uma consideração relevante sobre o jornalismo durante a ditadura militar é que a atuação da censura, em sua forma mais opressora, ocorreu apenas após 1968. Entre 1964 e 1968, a imprensa já noticiava, desde o golpe - em maior ou menor escala, dependendo do nível de alinhamento com o governo - a existência de movimentos, partidários ou populares, de protesto contra o regime. Embora já houvesse algumas restrições à produção de conteúdos informativos e culturais, de modo geral, a intervenção do regime na imprensa ocorria em casos esparsos, por meio de bilhetes ou telefonemas aos proprietários dos jornais, em que as autoridades militares se queixavam de determinadas matérias. Apenas em 13 de dezembro de 1968, quando foi decretado o AI-5, jornalistas e donos de jornais começaram a sentir o impacto e a violência da censura (ROSSI, 2008, p. 6).

De acordo com o relato de Clóvis Rossi, a notícia do novo Ato Institucional abalou os repórteres do Estado de S. Paulo e fez com que ficasse claro, no momento em que foi decretado, que a ditadura estava efetivamente instaurada. Diz o jornalista:

Até 1968 ainda dava [para divulgar certas informações]. É claro, com cuidado, com meias palavras, com entrelinhas - coisas que eu detesto fazer, mas era inevitável, indispensável. Até 1968 dá. Aí é que, em 1968, isso muda completa- mente. Eu me lembro bem que, na noite do AI-5, nós fechamos o jornal com a notícia do novo Ato Institucional e fomos reunir os repórteres e amigos, fomos para um boteco, (...) num ambiente de "o mundo acabou, não tem futuro, não tem horizonte, o que vai fazer, o que não vai fazer.” Enfim, todas as vias de futuro tinham sido fechadas (ROSSI, 2008, p.7).

O jornalista Pery Cotta, que trabalhava no Correio da Manbã, considera que o episódio mais dramático vivido por ele durante a ditadura militar ocorreu na noite em que foi decretado o AI-5. Ele afirma que a experiência de acompanhar de perto a ocupação da redação foi tão ruim que, depois disso, ele só permaneceu no jornal por mais alguns dias.

Quando a ditadura invade o jornal, quando o regime militar toma conta do jornal, [ele] mata a alma do jornal. É o fim do jornal, acho que foi aí, um fim anunciado, porque eles cortaram publicidade, jogaram bomba em agência do jornal, da principal agência do jornal (...) fizeram todo o cerceamento possível, estrangular financeiramente e comercialmente o jornal. Felizmente depois do AI-5 eu passei só cinco dias na redação do jornal porque me neguei a continuar escrevendo sobre política, pedi que me mandassem para outra área. Não me mandaram, disseram que eu teria que continuar escrevendo sobre política e no quinto dia me demitiram (COTTA, 2008, p.22).

Com base nos depoimentos de vários jornalistas que à época atuavam nas redações, é possível notar que, por um lado, nos jornais em que havia a presença física de um censor da Polícia Federal dentro da redação, a elaboração de estratégias para fugir da censura se tornava uma tarefa mais difícil. Por outro, a convivência com os censores possibilitava, em alguns casos, uma margem de negociação, que não existia nos veículos em que a censura prévia era feita nas sedes de órgãos do governo. Alguns jornalistas relembram que, em determinadas situações, a 
proximidade física com os agentes ajudava os repórteres a perceber os critérios usados no corte de matérias e o modo de atuação dos censores.

Ricardo Kotscho, então repórter de O Estado de S. Paulo, depõe:

Com o tempo, a gente começou a conviver com os censores e negociar com eles na oficina. Eu percebi que eles liam só o começo da matéria, se fosse assunto sério eles liam tudo, mas se fosse bobagem eles deixavam passar. Aí eu comecei a escrever com pirâmide invertida ao contrário, porque o jornalista tem sempre que abrir com o mais importante. Eu abria com qualquer abobrinha e deixava as coisas mais importantes para frente. Uns dias depois o cara percebeu, alguém falou com ele, e ele ficou bravo. A gente tinha essa relação com o censor, não tinha outro jeito (KOTSCHO, 2008, p. 8)

De acordo com Augusto Nunes, que também trabalhava em $O$ Estado de S. Paulo, o clima na redação sob censura prévia era o pior possível, pois pesava a autocensura: "O problema da censura é que (...) você cansa de escrever sabendo que vão cortar. (...) Quando vem a terceira matéria com aquele lápis vermelho, fica difícil você escrever" (NUNES, 2008, p.9).

Presidente do Sindicato dos Jornalistas do Rio de Janeiro durante o governo do general João Baptista de Figueiredo, José Carlos Monteiro analisa que, embora os chamados anos de chumbo tenham sido críticos para toda a imprensa, havia condições diferenciadas de trabalho e coação nos veículos. Ele relembra que, no jornal $O$ Globo, onde foi um dos editores do noticiário internacional, "o clima na redação era sufocante".

Os anos de chumbo no jornal foram tempos duros, tenebrosos. Apesar de Roberto Marinho ter apoiado, desde o começo, o movimento golpista, o jornal não escapou da repressão. Do ponto de vista profissional, pessoal e político, a atmosfera era um misto de perplexidade, desorientação, desalento e de uma grande disposição de resistência. Não era só a editoria de política que era visada pela censura. De forma geral e indiscriminada, a prática da censura atingia praticamente todos os setores da redação, até o setor de pesquisa e de arquivo. Quando eu fui para o Jornal do Brasil, as coisas melhoraram bastante, eu tive mais liberdade. Trabalhei na coluna Informe JB, que me permitia um maior espaço de resistência (MONTEIRO, 2012, p. 4).

\section{Censura e resistência}

No quadro de restrições à liberdade de expressão impostas pelo regime, as atividades jornalísticas acabaram, muitas vezes, superando os limites da profissão e se projetando no plano da resistência ao autoritarismo. Jornalistas, em diversos casos, tentaram resistir à censura, seja pela exploração de brechas e contradições dentro dos próprios veículos em que trabalhavam, seja se reunindo em projetos alternativos que visavam divulgar, dentro do possível, as informações que as empresas jornalísticas omitiam (ou por autocensura ou por adesão à ditadura).

Essas resistências objetivavam divulgar aspectos da realidade social, política e econômica que estavam sendo ignorados ou mascarados pelas empresas de mídia. Para isso, os profissionais tentavam realizar conteúdos (entrevistas, artigos, charges, poemas, fotografias, etc.) que evidenciassem os conflitos e os problemas vividos pelas diferentes classes sociais em plena época do chamado "milagre econômico". A propaganda do governo, que criava a imagem de um país cuja economia estava no auge do desenvolvimento, associada à censura às artes e à imprensa dificultaram a resistências de jornalistas.

Como enfatiza José Carlos Monteiro (2012, p. 5), é necessário lembrar que a maioria dos veículos de comunicação apoiava a ditadura desde o início. Também havia um contingente de jornalistas que tinha afinidade com valores e ideias do regime e, portanto, não aderiu à luta pela retomada da democracia. No entanto, para o desenvolvimento deste artigo, tomamos em conta a importância da ação de resistência. Em contraste com a complacência da maioria da grande imprensa da época, existia, por exemplo, a imprensa alternativa, que teve papel fundamental na luta pela democracia por denunciar violações dos direitos humanos e fazer críticas sistemáticas ao modelo econômico. As manifestações de oposição iam desde discussões político-intelectuais até brincadeiras descompromissadas de humor. Uma geração de desenhistas, como Henfil, Fortuna, Angeli, Loredano e
35 
Luiz Gê, fizeram parte de projetos alternativos com a publicação de charges satíricas de oposição ao governo (KUCINSKI, 1991).

Cabe realçar a participação de jornalistas que tentavam produzir informações verazes e até conteúdos críticos dentro da grande imprensa, apesar de todas as limitações. Quando não havia a presença do censor instalado na redação, a própria censura empresarial, em diversos veículos, restringia a liberdade de imprensa, eliminando textos contrários ao regime.

José Carlos Monteiro relembra que durante os anos de chumbo, as estratégias para driblar a censura no jornal O Globo tinham que ser bastante sutis. O jornalista conta:

Nós não tínhamos liberdade de informar criteriosamente, cuidadosamente o leitor sobre o que acontecia no mundo. Aos jornalistas o que cabia era descobrir maneiras, procedimentos de contornar essa censura, essa repressão. No nosso caso, dos jornalistas que trabalhavam nas grandes empresas de comunicação, além da censura do regime, estávamos sujeitos às regras da empresa. Por exemplo, escrevíamos matérias de apoio a movimentos literários, musicais, que prestigiassem o teatro brasileiro, o cinema, etc. Na hora da edição, colocávamos uma foto aqui, uma legenda ali. Mas os censores não eram burros. Eles chamavam a atenção da gente (MONTEIRO, 2012, p. 6).

Para Alberto Dines (2008), a experiência no Jornal do Brasil mostrou que cumprir as determinações da censura não significava necessariamente atender aos interesses do regime. Segundo ele, obedecer estritamente às ordens dadas pelas autoridades também poderia ser uma forma de desobedecer. Isto é, na visão do jornalista era possível acatar as ordens e, ao mesmo tempo, interpretá -las com liberdade. No dia da derrubada de Salvador Allende, a polícia ordenou que o jornal não usasse a notícia como manchete. A solução encontrada pelos jornalistas foi uma forma de conciliar a orientação recebida com uma mensagem subliminar de resistência.

Eu disse [aos colegas de redação]: 'a gente vai cumprir estritamente, eles não querem manchete, fazemos um jornal sem manchete... Vamos fazer um negócio: tira a manchete, vamos dar aí três ou quatro blocos, corpo o maior possível, contar essa história toda, sem manchete, e essa história, ela vai servir de manchete. Nós estamos cumprindo estritamente às ordens da censura, estamos fazendo um jornal em que o Allende não está na manchete'. Não esqueci dos telefonemas que eu recebi e do impacto que causou e a edição não sobrou nada, porque foi muito impactante para o leitor um jornal sem manchete (DINES, 2008, p. 43).

O jornalista relembra, ainda, outro episódio em que a equipe do Jornal do Brasil se reuniu para pensar em uma maneira de transmitir a notícia do decreto do AI-5, sem que o texto fosse cortado ou impedido de ser publicado. Os profissionais optaram por escrever uma manchete noticiosa, que apenas anunciasse a promulgação do novo ato e divulgasse o que todos no país já sabiam. Dessa forma, de acordo com ele, ninguém poderia contestar a informação. Ao longo da edição, outras táticas foram aplicadas para mostrar ao leitor que, a partir daquele momento, o jornal estava sob censura. $\mathrm{Na}$ previsão do tempo, os jornalistas escreveram, metaforicamente, que nuvens negras ameaçavam o país. $\mathrm{O}$ dia seguinte, no entanto, foi um dia de sol. Ele explica:

Todo o jornal, o jornal inteiro, até nos classificados, tinha coisas que indicavam que o jornal estava sob o controle de alguém e não mais dos jornalistas. Fotografias nas páginas de esporte... Me lembro que fechou muito tarde porque o jornal precisou ser feito e refeito, mas lembro perfeitamente também, às $5 \mathrm{da}$ manhã, já dia claro, dezembro, saímos, eu e o Carlos Lemos, que era o meu segundo, grande amigo e companheiro, saímos e falou: 'Olha, acho que fizemos uma edição histórica porque o Jornal do Brasil tomou uma posição, fez uma coisa que vai entrar para a história'. E efetivamente entrou (DINES, 2008, p. 43). 
Um outro recurso empregado em diversas publicações foi a introdução de informações fora de contexto. A estratégia visava protestar contra a falta de liberdade de imprensa e de expressão e, em alguns casos, revelar ao leitor, de forma discreta, que o veículo estava sob censura. O jornalista Mino Carta exemplifica esse tipo de tentativa citando um episódio ocorrido na revista $V e j a$ durante a ditadura.

Nós começamos a publicar estranhos textos, debaixo, se não me engano, da rubrica História. Eram fantasias que inventávamos para ludibriar os censores e divertir as nossas famílias. Reescrevemos a história das Cruzadas com destaque para o general Drapeau, que era uma sátira do general Bandeira (...) Os censores não entendiam nada (PEREIRA, 2011, p. 124).

Essas difíceis experiências de censura e resistência tiveram uma ressonância que ultrapassa os anos de ditadura. Além dos esforços para tentar burlar a vigilância do regime e transmitir informações sobre a realidade política e social do país, devemos considerar também a contribuição de jornalistas na construção de uma memória coletiva sobre o processo político pós-1964, sobretudo no período mais agudo de censura e repressão (que perdurou até a segunda metade da década de 1970), por meio de seus relatos, lembranças e reavaliações críticas.

\section{Memória jornalística como parte de uma me- mória social}

Devemos, antes de tudo, considerar que a memória dos jornalistas que exerceram a profissão nos anos de chumbo, para além de seu caráter de subjetividade e individualidade, tem capacidade de revelar uma dimensão social e histórica mais ampla, inclusive explicitando novas interpretações sobre acontecimentos e circunstâncias vividos. Marialva Barbosa analisa:

A ação do jornalista é, sobretudo, de natureza memorialística, já que a memória é uma operação do presente e conformadora da própria identidade. Mas, ao construir uma dada memória na sociedade, na verdade estariam [os jornalistas] configurando uma identidade da própria profissão (BARBOSA, 2004, p.1).
Desta forma, as reflexões feitas pelos jornalistas não são simplesmente reminiscências e avaliações de uma experiência individual ou isolada. Na verdade, a memória pessoal de cada um deles é também parte de uma memória social, que corresponde aos grupos e às categorias sociais nos quais eles se incluem (BOSI, 1994, p. 39).

Eles têm uma dupla importância na construção da memória do jornalismo durante a ditadura militar. Primeiro, foram os responsáveis por selecionar, processar e divulgar dados, fatos, informações e denúncias para deveriam ser levados ao conhecimento público. Nem sempre conseguiram cumprir plenamente a sua missão, pois enfrentaram, em muitos casos, as barreiras impostas pelas censuras governamental e empresarial. Mesmo assim, os materiais produzidos, dentro das limitações vigentes, contribuíram significativamente para lançar luzes sobre o período. As coleções de jornais e revistas atestam o que dissemos, pois proporcionam uma percepção geral da sociedade e do país na moldura do autoritarismo, a despeito da supressão e do silenciamento de uma série de ocorrências, ou do tratamento que as notícias recebiam e que nem sempre correspondiam às situações efetivamente vividas (sobretudo no campo político, o mais atingido pelos mecanismos de controle da informação ditados ou recomendados pelo regime). Agora, quase 30 anos após a retomada da democracia, a memória e o discurso das mesmas personagens voltam a ser importantes no sentido de ajudar a revelar e a recompor fragmentos daquela realidade, que ainda necessita ser recontada e repensada, a partir de uma perspectiva atual.

Como produtores de discursos, os jornalistas realizam, diariamente, o exercício de lembrança e esquecimento ao priorizar determinadas informações em detrimento de outras. Avaliam, selecionam e tratam, conforme regras e dinâmicas específicas, o que pode e deve ser registrado ou ignorado. Na análise de Marialva Barbosa, "a memória é parte essencial do trabalho jornalístico porque, através dela, o profissional seleciona constantemente elementos para construir a história do passado e fixar o que deve ser lembrado no futuro" (BARBOSA, 2005, p. 108).

Maurice Halbwachs argumenta que a lembrança não é uma linear repetição do passado, mas um instrumento de reconfiguração dos fatos, a partir das experiências presentes, uma vez que contextos diversos geram constantes mudanças na sociedade. São esses contextos que associam e selecionam o passado para espelhar o presente e visualizar o futuro (HALBWACHS, 1990).

Assim, a memória individual dos profissionais da mídia expõe a dimensão social e histórica de outra 
história, mais ampla, em sua temporalidade - no caso, a própria atividade jornalística durante o regime militar -, que envolve segmentos inteiros da cada categoria profissional, e não apenas um percurso único e singular.

Nessa perspectiva, é necessário levar em consideração a análise de Paul Veyne sobre a relevância do resgate e da reapreciação das experiências vividas no processo histórico-social:

Aquilo que individualiza os eventos históricos não é precisamente a marca pessoal, nem a 'diferença de detalhes', mas, sobretudo, aquilo que os eventos são, isto é, o fato de que acontecem num dado momento; a história nunca se repetiria, mesmo que vivesse a contar a mesma coisa (VEYNE, 2008, p. 22).

Cada trajetória profissional rememorada compõe um mosaico de fatos e acontecimentos vivenciados por inúmeras pessoas, em circunstâncias histórico-sociais semelhantes. Ou seja, como ressalta Norbert Elias, a memória individual não é apenas uma manifestação da individualidade de cada um. As memórias particulares orientam "a compreensão dos sistemas de representação que um grupo faz, não apenas de si mesmo, mas, sobretudo, dos outros e da configuração histórica e social em que se acha inserido" (ELIAS, 2001, p.120).

A multiplicidade de memórias e de discursos pode contribuir para a escrita de uma versão plural da história do país e, nesse caso específico, do jornalismo brasileiro. A psicanalista Madalena Sapucaia argumenta que o resgate de memórias individuais desempenha a função imprescindível de ampliar debates sobre acontecimentos passados relevantes:

Os grupos de força têm um papel dominante na formação do imaginário coletivo. Existem poucas vozes que criam uma versão oficial de histórias construídas. No caso específico do Brasil, o senso comum é estabelecido, em grande parte, por uma mídia que é totalmente inconfiável. Por isso, é fundamental resgatarmos memórias singulares sobre episódios relevantes do passado, até para a construção de uma identidade nacional (SAPUCAIA, 2012, p. 3).
Trata-se, então, de reexaminar um contexto compartilhado, em maior ou menor intensidade, por grande parte da categoria profissional. O que vai distinguir uma experiência da outra são as peculiaridades de cada veículo, de cada redação, de cada rotina de trabalho. Também há diferenças na reavaliação que os jornalistas fazem hoje em dia de suas participações no período, já que a história de vida de cada um altera o modo de refletir sobre o passado. Mas o quadro geral abordado possui uma série de pontos de convergências e afinidades, como, por exemplo, as visões que determinados grupos de jornalistas tinham sobre o papel da imprensa na resistência ao autoritarismo, as barreiras ao pleno exercício da liberdade de expressão, o alinhamento da maioria das empresas jornalísticas com a ditadura, os interesses ideológicos e políticos em jogo, os espaços possíveis para a difusão de informações não comprometidas com a lógica do regime e a importância da resistência cultural à ditadura.

\section{Jornalismo, memória e produção de sentido}

A memória é um processo de produção de sentido, os fatos do passado são sempre recordados dependendo do significado e do grau de importância que possuem para quem os recorda. O jornalismo, como importante instrumento de produção de sentido sobre a realidade social, sofre influência das condições específicas de cada contexto e de cada veículo em que atuam os profissionais. No caso aqui focalizado, os jornalistas enfrentaram condições extremamente peculiares e muitas vezes desfavoráveis à livre expressão, já que eram intensos o controle e a manipulação dos noticiários.

Devemos compreender o papel crucial da memória na reconstituição dos fatos e circunstâncias que envolveram a prática jornalística nos anos de repressão. A memória não é um fato e, sim, uma construção que se relaciona com as identidades sociais, estando sempre atrelada ao ponto de vista de um grupo social específico ao qual a pessoa pertence. "Assim, a memória individual nunca é, exclusivamente, a manifestação de uma singularidade individual - já que nela falam as vozes coletivas de constituição do sujeito e, de resto, da sociedade" (BATISTA; SOUZA, 2011, p. 5). Como explica Halbwachs (1990), as lembranças, apesar de pertencerem aos indivíduos, fazem parte da sociedade e do contexto em que os sujeitos estão inseridos.

A lembrança pode ser descrita da seguinte forma, na visão de Marialva Barbosa: 
Seletiva reconstrução do passado, baseada em ações subsequentes, não localizadas nesse passado, em percepções e em novos códigos, é através da memória que se delineia, simboliza e classifica do mundo. O passado é, pois, universo de significados, disputados conflitivamente no presente. Por outro lado, a memória está sujeita a enquadramentos: escolhese o que vai ser lembrado e o que deve ser esquecido (BARBOSA, 2004, p. 5).

A memória pode se originar em acontecimentos vividos pela própria pessoa ou, no caso do senso comum, fazer parte de um imaginário construído no contexto social em que o sujeito se insere. Pollak esclarece:

Em primeiro lugar, os acontecimentos vividos pessoalmente. Em segundo lugar, são os acontecimentos que eu chamaria de 'vividos por tabela', ou seja, acontecimentos vividos pelo grupo ou pela coletividade à qual a pessoa sente pertencer. São acontecimentos dos quais a pessoa nem sempre participou, mas que, no imaginário, tomaram tamanho relevo que, no fim das contas, é quase impossível que ela consiga saber se participou ou não. (...) É perfeitamente possível que ocorra (...) um fenômeno de projeção ou de identificação com determinado passado, tão forte, que podemos falar numa memória quase herdada (POLLAK, 1992, p. 201).

Madalena Sapucaia (2012) tem uma outra visão. A psicanalista afirma que, para discutir o tema memória, é imprescindível estabelecer uma análise conceitual sobre os termos "memória afetiva", "memória individual" e "memória coletiva". Segundo a especialista, o ponto central da questão é compreender que as lembranças são, em todos os casos, construções feitas pelo indivíduo, com base em episódios que o marcaram. Isto é, os discursos sobre vivências do passado carregam consigo uma carga inevitável de emoção - consciente ou não. Assim, toda memória é, em si, afetiva e não há separação entre ela e a própria pessoa. O segundo aspecto que envolve a temática, para ela, é que, embora seja usual falar em memória coletiva, não existe, de fato, distinção entre memórias coletiva e individual. De acordo com Sapucaia:

(...) Não temos uma memória coletiva porque o coletivo tem memórias individuais. Todas as lembranças são individuais e particulares. Portanto, também não podemos afirmar que exista uma memória coletiva da ditadura militar no Brasil. Há, na verdade, memórias e discursos individuais, baseados em visões de mundo específicas, que são colocados para a sociedade como verdade. Podemos, sim, falar na existência de um senso comum que sofre influências fortes dos grupos de poder. (SAPUCAIA, 2012, p. 5).

Sem dúvida alguma, os grandes veículos de comunicação fazem parte desses restritos grupos de força que contribuem para a formação de um senso comum acerca de determinados momentos históricos. É necessário perceber também que os jornalistas são responsáveis, em grau ponderável, pela construção de determinadas visões sobre o processo sociopolítico do país. Nesse sentido, procuramos demonstrar que, nos estudos sobre as condições objetivas de exercício do jornalismo durante a ditadura militar, as lembranças dos acontecimentos vivenciados por eles constroem um mosaico mais amplo de sua atuação, que engloba uma variedade de iniciativas individuais, ações de grupos, atitudes, sentimentos e reações dentro das redações.

Além disso, em um sentido mais amplo, a memória dos jornalistas assume, neste trabalho, um crucial papel de possibilitar novas avaliações e reflexões sobre um capítulo da história do país que não deve ser esquecido. Isto é: resgatar o que os jornalistas retiveram de seus embates com a truculência do regime militar significa a possibilidade de se passar a limpo acontecimentos e episódios de um tempo de obscurantismo, que afetou profundamente a imprensa, a sociedade e os destinos do país.

Do ponto de vista acadêmico, o presente artigo realça a importância de uma ampliação da reflexão crítica sobre a história da profissão no país e o enorme potencial do jornalista como agente de transformação social. Em um momento de enorme despolitização e de desinteresse generalizado pelas questões sociais, políticas

39

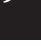


e culturais, consideramos essencial a retomada de temas que ajudem a pensar o sentido de existência da profissão.

\section{Referências}

AQUINO, Maria Aparecida de. Censura, imprensa, estado autoritário (1968-1978). Bauru: 1999.

ARAÚJO, Angela de Aguiar. A imprensa brasileira e a política nos anos 1960 e 1970: "esvaziamento político" ou "lugar de descoberta" da memória social? In: ENCONTRO DE HISTÓRIA DA MÍDIA, 4., 2005. São Luis do Maranhão: ALCAR, 2005. p. 5-20.

BARBOSA, Marialva. História cultural da imprensa - 19002000. Rio de Janeiro: Mauad X, 2007.

BARBOSA, Marialva. Jornalismo e a construção de uma memória para sua História. In: BRAGANÇA, Aníbal \& MOREIRA, Sônia Virgínia (org). Comunicação, acontecimento e memória. São Paulo: Intercom, 2005, p. 102-111.

BARBOSA, Marialva, Jornalistas, "senhores da memória?. In: CONGRESSO BRASILEIRO DE CIÊNCIAS DA COMUNICAÇÃO, 27., 2004. Porto Alegre: Intercom, 2004. p. 1-13.

BATISTA, Cicélia Pincer \& SOUZA, Vanderlei Dias de. Histórias de jornalistas: a narrativa da memória de profissionais como possibilidade de construção do conhecimento sobre a história do jornalismo. In: CONGRESSO BRASILEIRO DE CIÊNCIAS DA COMUNICAÇÃO, 34., 2011. Recife: Intercom, 2011. p. 1-15.

BOSI, Ecléa. Memória e sociedade: lembranças de velhos. São Paulo: Companhia das Letras, 1994.

COTTA, P. Depoimento [22 de julho de 2008]. Rio de Janeiro: Centro de Cultura e Memória do Jornalismo. Entrevista concedida a Carla Siqueira e Caio Barretto. Disponível em: http://www.ccmj.org.br/sites/default/ files/pdf/5/Arquivo \%20para\%20download_20.pdf Data de acesso: 6 de setembro de 2012.

DINES, A. Depoimento [17 de setembro de 2008]. Rio de Janeiro: Centro de Cultura e Memória do Jornalismo. Entrevista concedida a Carla Siqueira e Caio Barretto. Disponível em: http://www.ccmj.org.br/sites/default/ files/pdf/5/ALBERTO_DINES\%20final.pdf. Data de acesso: 28 de março de 2014.
ELIAS, Norbert. Elias por ele mesmo. Rio de Janeiro: Jorge Zahar Editor, 2001.

FICO, Carlos. Versões e controvérsias sobre 1964 e a ditadura militar. In: Revista Brasileira de História. São Paulo, vol. 24, n. 47, 2004. p. 29-60.

HALBWACHS, Maurice. A memória coletiva. São Paulo: Vértice, 1990.

KOTSCHO. R. Depoimento [10 de agosto de 2008]. Rio de Janeiro: Centro de Cultura e Memória do Jornalismo. Entrevista concedida a Carla Siqueira e Caio Barretto. Disponível em: http://www.ccmj.org.br/video-detalhes/607 Data de acesso: 4 de setembro de 2012.

KUCINSKI, Bernardo. Jornalistas e revolucionários; nos tempos da imprensa alternativa. São Paulo: Scritta, 1991.

MONTEIRO, J. C. Jornalismo e ditadura militar no Brasil: da censura à resistência nas redações: depoimento. [26 de setembro, 2013]. Quito: América Latina en Movimiento. Entrevista concedida a Lívia Assad de Moraes.

NUNES, A. Depoimento [27 de setembro de 2008]. Rio de Janeiro: Centro de Cultura e Memória do Jornalismo. Entrevista concedida a Carla Siqueira e Caio Barretto. Disponível em: http://www.ccmj.org.br/sites/default/ files/pdf/5/Arquivo\%20para\%20download_5.pdf Data de acesso: 8 de setembro de 2012.

PEREIRA, Fábio. Jornalistas intelectuais no Brasil. São Paulo: Summus, 2011.

POLLAK, Michael. Memória e identidade social. In: Estudos Históricos. Rio de Janeiro, vol. 5, n. 10, 1992. p. 200-212.

POLLAK, Michael. Memória, esquecimento, silêncio. In: Estudos Históricos, Rio de Janeiro, vol. 2, n. 3, 1989. p. 3-15.

ROSSI, C. Depoimento [26 de setembro de 2008]. Rio de Janeiro: Centro de Cultura e Memória do Jornalismo. Entrevista concedida a Carla Siqueira e Caio Barretto. Disponível em: http://www.ccmj.org.br/sites/default/ files/pdf/5/Arquivo \%20para\%20download_12.pdf Data de acesso: 15 de junho de 2012.

SAPUCAIA, M. Depoimento [2 de outubro de 2012]. Rio de Janeiro. Entrevista concedida a Lívia Assad de Moraes. 
VEYNE, Paul. Como se escreve a história; Foncault revoluciona

a história. Brasília: Editora da UnB, 2008. 